\title{
EDITORIAL
}

\section{Duazary: sus logros, avances y aportes a la comunidad científica}

\section{Duazary: his achievements, advances and contributions to the scientific community}

\author{
Oskarly Pérez-Anaya ${ }^{1}{ }^{1}$, Guillermo Augusto Ceballos-Ospino (iD) ${ }^{2}$
}

1. Coeditor de la revista Duazary. Universidad del Magdalena. Santa Marta, Colombia. Correo: oskperez123@gmail.com - https://orcid.org/00000002-0701-7847

2. Editor de la revista Duazary. Universidad del Magdalena. Santa Marta, Colombia. Correo: guillermoceballos@gmail.com https://orcid.org/0000-0002-1568-7058

Estimados lectores en este breve escrito anunciamos nuestro más reciente logro, aunque no el primero: Duazary se ha posicionado como la primera revista en Ciencias de la Salud del Caribe colombiano según la última medición de la Convocatoria para indexación de revistas científicas colombianas especializadas - Publindex 2020, por haberse clasificado, por segunda vez en su historia, en categoría $B$; siendo la única de esta región con dicha clasificación. Por supuesto, esto es, en gran parte, gracias a ustedes, que a veces han fungido como autores y otras como revisores garantizando la publicación de trabajos de contenido científico relevante.

Duazary, que en lengua indígena de la Sierra Nevada de Santa Marta significa salud integral, completa este año, 17 años de existencia, 13 de ellos con clasificación ininterrumpida de Publindex Minciencias e indexada en más de 30 bases, repositorios, catálogos e índices bibliográficos, que en conjunto permiten que sus estándares de calidad cada día sean más rigurosos y contribuyan a la mejora del contenido, que a esta se somete, para una eventual publicación. Su periodicidad ha cambiado a lo largo de los años. Desde su creación (2004) hasta el 2017 fue semestral. En 2018 se optó por publicar tres números por año y en 2020 se pasó a periodicidad trimestral, es decir, a lanzar un número cada tres meses; buscando este año publicar entre 35 y 40 artículos, cifra que en la revista nunca se ha alcanzado, pero que permitirá dar la oportunidad a que más investigadores den a conocer sus trabajos. Duazary cada vez más se gana la confianza de la comunidad científica, evidencia de ello es que, en los volúmenes de los últimos años, se observan manuscritos de investigadores de distintas instituciones del país y de más de 20 países del continente americano y europeo ${ }^{1}$.

La convocatoria de medición de revistas de Publindex de 2021, apuntamos a conservar la misma categoría, para la que se estima se requerirá entre otras características, un índice H5 (2016-2020) de 11 o 12, muy similar a la del año pasado, en donde Duazary alcanzó un H5 (2015-2019) de 12. A marzo del presente año el $\mathrm{H} 5$ de la revista está en 11, con un posible tope de 15 al finalizar el año, según una estimación hecha con el software Publish Or Perish, que es el mismo que utiliza Publindex para medir el H5 de las revistas científicas que participan en la convocatoria desde 2016.

Por último, entre los propósitos que se tienen en los próximos años para Duazary, es lograr el ingreso a SCOPUS y con ello a un cuartil en el SCImago Journal Rank (SJR), para lo cual nos hemos venido preparando hace un lustro. Nuevamente gracias a nuestros lectores, autores y revisores, esperamos disfruten del número 2 de 2021, que trae temas interesantes y de impacto para nuestra región y el país. 


\section{REFERENCIAS BIBLIOGRÁFICAS}

1. Pérez-Anaya O, Ceballos-Ospino G, GonzálezGélvez D, Suescún-Arregocés J. Análisis bibliométrico de la revista Duazary en el quinquenio 2012-2016. Duazary. 2017; 14 (2): 122 - 130. Doi: http://dx.doi.org/10.21676/2389783X.1973

2. Ceballos-Ospino GA, Pérez-Anaya O. Duazary: sus procesos y avances editoriales. Duazary. 2017;14(2):120-1. Disponible en: https://doi.org/10.21676/2389783X.1974 